\title{
Perceived risk of regular cannabis use in the United States from 2002 to 2012: differences by sex, age, and race/ethnicity*
}

\author{
Lauren R. Pacek ${ }^{\mathrm{a}}$, Pia M. Mauro ${ }^{\mathrm{b}}$, and Silvia S. Martins $\mathbf{s}^{\mathrm{c}, \mathrm{b}}$ \\ Lauren R. Pacek: Ipacek@jhmi.edu; Pia M. Mauro: pmauro1@jhu.edu; Silvia S. Martins: ssm2183@columbia.edu \\ aJohns Hopkins University School of Medicine, Department of Psychiatry and Behavioral \\ Sciences, 5510 Nathan Shock Drive, Room 1708 Baltimore MD, 21224 \\ bJohns Hopkins University Bloomberg School of Public Health, Department of Mental Health, 624 \\ N. Broadway, Room 894 Baltimore, MD 21205 \\ ${ }^{\circ}$ Columbia University Mailman School of Public Health, Department of Epidemiology, 722 West \\ $168^{\text {th }}$ Street, Room 509 New York, New York 10032
}

\section{Abstract}

Introduction-Cannabis is one of the most widely used psychoactive substances in the United States (U.S.). Perceived risk of use is associated with substance use; the recent debate surrounding medicalization and legalization of cannabis in the U.S. has the potential to impact perceived risk of use. Recent estimates are needed to assess temporal changes in, and identify correlates of, perceived risk of cannabis use.

Methods-Utilizing data from the 2002-2012 survey years of the National Survey on Drug Use and Health, chi-squared statistics and logistic regression were used to describe temporal changes in perceived risk of regular cannabis use (i.e., once or twice a week), to explore correlates of perceived risk, and to report frequency of cannabis use.

Results-Between 2002-2012, perceived great risk of regular cannabis use varied significantly overall $(p<0.001)$. The prevalence of past year non-daily $(p<0.001)$ and daily use varied

\footnotetext{
* Supplementary material can be found by accessing the online version of this paper at http://dx.doi.org and by entering doi:... (C) 2015 Published by Elsevier Ltd.

Correspondence to: Lauren R. Pacek, lpacek@ jhmi . edu.

Contributors

Author Pacek conceptualized the research question and wrote the first draft of the manuscript. Authors Mauro and Martins contributed to statistical analyses and subsequent drafts of the manuscript. All authors contributed to and have approved of the final version of the manuscript.

Conflict of interest

Author Martins serves as a consultant to Purdue Pharma, L.P., unrelated to the present work. The authors have no other conflicts of interest to declare.

Publisher's Disclaimer: This is a PDF file of an unedited manuscript that has been accepted for publication. As a service to our customers we are providing this early version of the manuscript. The manuscript will undergo copyediting, typesetting, and review of the resulting proof before it is published in its final citable form. Please note that during the production process errors may be discovered which could affect the content, and all legal disclaimers that apply to the journal pertain.

Disclaimer

Role of funding source

This work was funded by the following grants: T32 DA007209 (Pacek, P.I.: George Bigelow), T32 DA007292 (Mauro, P.I. C. Debra Furr-Holden), and R01 HD060072 (P.I. Martins).
} 
significantly during this time $(p<0.001)$. Controlling for survey year and other confounders, characteristics associated with increased odds of perceived great risk of regular cannabis use included: female sex; Non-White race/ethnicity; age 50+; and family income of \$20,000-49,999. Characteristics associated with decreased odds of perceived great risk included: ages 12-17 and $18-25$; high school education or greater; total family income of $\$ 75,000+$; past year non-daily and daily cannabis use; and survey years 2008-2012.

Conclusions-Findings characterize trends of perceived risk of regular cannabis use, and past year non-daily and daily cannabis use. Longitudinal studies of the influence of legal status of cannabis at the state-level are needed.

\section{Keywords}

cannabis; perceived risk; NSDUH

\section{INTRODUCTION}

Cannabis is one of the most commonly used psychoactive substance in the United States (U.S.), with 7.3\% of the U.S. general population reporting use in the past month in 2012 (SAMHSA, 2013). The widespread use of cannabis is of public health importance; cannabis use is associated with a host of social, psychological, and physical impairments, including financial difficulties, low energy levels, dissatisfaction with productivity levels, sleep and memory issues, and relationship and family problems (Gruber et al., 2003; Stephens et al., 2002). Most individuals receiving cannabis use disorder (CUD) treatment report difficulty quitting, and experience a withdrawal syndrome after cessation (Budney et al., 2007a). In light of the negative effects of cannabis use, continued examination of characteristics that are associated with cannabis use, particularly regular cannabis use, is prudent.

Prior research has identified numerous factors associated with cannabis use. Factors associated with cannabis use can differ among sex and age subgroups (Copeland and Swift, 2009; Guxens et al., 2007), warranting the need for stratified analyses. Cannabis use is associated with lower education achievement (Lynsky and Hall, 2000; Fergusson et al., 2003), lower productivity at work, higher neighborhood disorder and disadvantage (Wilson et al., 2005; Furr-Holden et al., 2011; Tucker et al., 2013), and higher risk of other illicit drug use (Lynskey et al., 2003). Regular cannabis use can lead to CUDs, particularly among individuals who initiate cannabis use early and have other risk factors such as using other substances, having substance-using peers, and reporting anxiety and depressive symptoms (Hall and Degenhardt, 2007; Wittchen et al., 2007; Buckner et al., 2008), and are more prevalent among males and younger adults (Compton et al., 2004; Copeland and Swift, 2009). A longitudinal study indicated that the probability of CUD increased with the increasing presence of risk factors for CUD (Brook et al., 2011). Moreover, there is an inverse relationship between marijuana use and perceptions of its harmfulness (Compton et al., 2005).

According to the Health Belief Model (Janz and Becker, 1984), perceived risk is an important factor in deciding whether or not individuals will engage in health-related behaviors. Continually evolving regulations governing the medicalization and legalization of 
cannabis use within the U.S. have the potential to impact perceived risk of cannabis use, which may influence individuals' decisions to use cannabis. Cerda and colleagues (2012) showed that adults in states with medical cannabis laws have higher odds of cannabis use than residents of states without such laws. Compared to those without medical marijuana laws, National Survey on Drug Use and Health (NSDUH) participants in states with medical marijuana laws also had lower perceptions of risk associated with use as well as adolescent marijuana use (Wall et al., 2011). In Colorado, marijuana commercialization was also associated with decreased perception of great risk of marijuana use for adolescents and adults alike (Schuermeyer et al., 2014). Conversely, in an analysis of the National Survey on Drug Use and Health 2002-2009 data, Harper and colleagues (2012) found limited evidence for a causal effect of the presence of medical marijuana laws-in 2002-2003 8 states had legalized the use of medical marijuana, whereas in 2007-2008, 13 total states had medical marijuana laws - on measures of reported cannabis use. However, despite extant studies investigating perceived risk surrounding cannabis use (Lopez-Quintero and Neumark, 2010; Kilmer et al., 2007), and annual publications put out by the Substance Abuse and Mental Health Services Administration (SAMHSA), to our knowledge, no current research describes temporal changes in perceived risk of cannabis use using the most recent decade of aggregated data of the U.S. population 12 years and older. In particular, this gap includes perceived risk of regular use, temporal changes in frequency of cannabis use, subgroup analyses for each of the aforementioned temporal trends, and characteristics associated with perceived risk of use using a U.S. nationally representative sample.

To address current gaps in the literature, the present study had the following aims: 1) to examine the change in prevalence of perceived great risk of regularly using cannabis (i.e., once or twice a week) over an 11-year period using the most recent currently available NSDUH survey data (i.e., during the years 2002-2012), stratified by sex; and 2) to explore characteristics associated with perceived great risk of cannabis use. To accomplish these aims, we used data from a nationally representative survey of non-institutionalized individuals ages 12 and older living in the U.S.

\section{METHODS}

\subsection{Sample}

Data were obtained from the $2002(n=54,079), 2003$ ( $n=55,230), 2004$ ( $n=55,602), 2005$ ( $n=55,905), 2006$ ( $n=55,279), 2007$ ( $n=55,435), 2008$ ( $n=55,739), 2009$ ( $n=55,772), 2010$ $(n=57,873), 2011(n=58,397)$, and $2012(n=55,268)$ National Survey on Drug Use and Health (NSDUH) public use data files, a combined total sample size of 614,579 U.S. individuals. The NSDUH, sponsored by the Substance Abuse and Mental Health Services Administration (SAMHSA), was designed to provide estimates of the prevalence of extramedical use of legal and illegal drugs in U.S. community-based individuals aged 12 and older (SAMHSA, 2003, 2013). The survey employed a 50-state design with an independent multistage area probability sample for each of the 50 states and the District of Columbia. To increase the precision of estimates, African-Americans, Hispanics, and young people were oversampled. Response rates for completed surveys ranged from $73 \%-79 \%$. 
Informed consent was obtained before the start of every interview. Participants were given a description of the study, read a statement describing the legislation regarding the confidentiality of any information provided by participants, and assured that participation in the study was voluntary. Additional information on data confidentiality maintenance is available elsewhere (SAMHSA 2003, 2013). Surveys were administered by computerassisted personal interviewing (CAPI) conducted by an interviewer and audio computerassisted self-interviewing (ACASI). Use of ACASI was designed to provide respondents with a private and confidential means of responding to questions, and to increase honest reporting of illegal drug use and other sensitive behaviors (SAMHSA, 2003, 2013). Respondents were offered U.S. \$30 for participation. The analyses were based on deidentified publicly available data exempt from Institutional Review Board review.

Sampling weights for the NSDUH were computed to control for unit-level and individuallevel non-response, and were adjusted to ensure consistency with population estimates obtained from the U.S. Census Bureau. In order to use data from the 11 years of combined data, a new weight was created upon aggregating the 11 datasets by dividing the original weight by the number of data sets combined. Further descriptions of the sampling methods and survey techniques for the NSDUH are found elsewhere (SAMHSA, 2003, 2013).

\subsection{Measures}

2.2.1 Socio-demographic variables-Socio-demographic variables for this study included sex, race/ethnicity, age, marital status, educational attainment, and survey year. Age (12-17; 18-25; 26-49; 50+) and race/ethnicity (White; Black; Hispanic; Other), and total family income $(\$ 0-19,000 ; \$ 20,000-49,000 ; \$ 50,000-74,999 ; \$ 75,000+)$ were treated as categorical variables. Educational attainment (less than high school; high school graduate or greater) was dichotomized.

2.2.2 Perceived risk of cannabis use and past year cannabis use-Participants reported perceived risk of using cannabis on a regular basis (i.e., smoking cannabis once or twice a week): "How much do people risk harming themselves physically and in other ways when they smoke [cannabis] once or twice a week?" Response options included "no risk", "slight risk", "moderate risk", and "great risk". In the present analyses, perceived risk was dichotomized as "great perceived risk" versus "other perceived risk".

Participants reported whether they ever used cannabis in their lifetime, and how long it had been since their last cannabis use. Participants who reported using cannabis "Within the past 30 days" or "More than 30 days ago but within the past 12 months" were categorized as past year users in a new dichotomous variable. Participants indicating past year use reported the number of days they used cannabis in the last 12 months. Participants who reported using cannabis on 300 days or greater were classified as "daily users" (Budney et al., 2003, 2007b; Moore and Budney 2003; Whitlow et al., 2004), while those reporting use on 299 days or less in the past year were classified as "non-daily users". A three-level variable for cannabis use was created to categorize respondents by frequency of past year cannabis use: $0=$ no use, $1=$ non-daily use, $2=$ daily use. 


\subsection{Statistical analysis}

Data were weighted to reflect the complex design of the NSDUH sample and were analyzed with STATA SE version 12.0 software (StataCorp, 2011). We used Taylor series estimation methods (STATA "svy" commands) to obtain proper standard error estimates for the crosstabulations. Participants were stratified by survey year (2002-2012). For both perceived risk and past year use outcomes, cross-tabulations were performed separately for the total sample, as well separately for men and women; within sex, cross-tabs were calculated separately for each of the four race/ethnicities and age groups. Chi-square $\left(\chi^{2}\right)$ tests were used to identify differences between 2002-2012 in each one of the following strata: 1) perceived great risk of regular cannabis use; 2) perceived risk of regular cannabis use among past year non-users, past year non-daily users, and past year daily users; and 3) past year non-daily cannabis use and past year daily cannabis use. Multivariate logistic regression analyses were used to determine the association between socio-demographic and cannabis use characteristics with perceived great risk of regular cannabis use. Analyses were adjusted for sex, age, race/ethnicity, education, total family income, past year cannabis use status, and survey year. To mitigate concerns about multiple comparisons and possible inflation of Type-1 error, Bonferroni-corrected alpha levels of 0.002 were used for all analyses.

\section{RESULTS}

\subsection{Perceived risk of regular cannabis use: 2002-2012}

3.1.1 Total sample-Table 1 contains the distribution of perceived risk of regular cannabis use in each survey year, prior to dichotomization. After dichotomizing the perceived risk variable, the percentage of participants who perceived a great risk associated with regular cannabis use varied significantly between 2002 and $2012 \chi^{2}(10, N=607,324)=$ $109.81, p<0.001$. In 2002, 51.3\% of NSDUH participants perceived a great risk associated with regular cannabis use, versus $40.3 \%$ of participants in 2012 . This $11.0 \%$ decrease was statistically significant, $\chi^{2}(d f=1, N=108,026)=341.40, p<0.001$ (Table 2). Similar variation across the decade, and significant decreases in perceived great risk were observed for all other race/ethnicity and age categories in the full sample, with the following exceptions where significant variation between 2002-2012 was not observed: participants of Other race/ethnicity age $26-49 \chi^{2}(10, N=11,641)=2.87, p=0.004$ and age $50+\chi^{2}(10, N=3,267)$ $=1.92, p=0.051$.

3.1.2 Men-Perceived great risk of regular cannabis varied significantly between 2002$2012 \chi^{2}(1, N=292,106)=46.61, p<0.001$ and decreased from $43.2 \%$ in 2002 to $33.5 \%$ in 2012 among men $\chi^{2}(1, N=51,871)=155.82, p<0.001$ (Supplemental Table $1 \mathrm{a}^{1}$ ). Similar to the full sample, decreases in perceived great risk were observed for most race/ethnicity and age categories among men. Notable exceptions to this observation, where perceived great risk of regular use did not change significantly across time, included Black men ages 50+, $\chi^{2}(1, N=2,339)=5509.60 p=0.349$, Hispanic men ages $50+, \chi^{2}(1, N=1,903)=2.73$, $p=0.005$, and men of Other race/ethnicity ages $26-49, \chi^{2}(1, N=5,399)=2.54, p=0.007$, as well as respondents ages $50+\chi^{2}(1, N=1,487)=1.81, p=0.064$.

\footnotetext{
${ }^{1}$ Supplementary material can be found by accessing the online version of this paper at http://dx.doi.org and by entering doi:...
} 
3.1.3 Women-Between 2002 and 2012, perceived great risk of regular cannabis use varied significantly $\chi^{2}(10, N=315,218)=74.73, p<0.001$, and the prevalence of perceived great risk decreased from $58.8 \%$ in 2002 to $46.7 \%$ in 2012 among women $\chi^{2}(1, N=56,155)$ $=252.38, p<0.001$ (Supplemental Table $\left.1 b^{2}\right)$. Exceptions to the observed variation in perceived great risk among women came among Hispanic women age $50+\chi^{2}(10, N=$ $2,459)=1.35, p=0.215$, as well as among women of Other race/ethnicity $\chi^{2}(10, N=25,569)$ $=2.90, p=0.003$, age 12-17 $\chi^{2}(10, N=8,610)=1.99, p=0.043$, age 26-49 $\chi^{2}(10, N=6,242)$ $=1.83, p=0.067$, and age $50+\chi^{2}(10, N=1,780)=1.21, p=0.288$.

\subsection{Perceived risk of cannabis use among past year cannabis non-users: 2002-2012}

3.2.1 All Past Year Cannabis Non-Users-Among past year cannabis non-users overall, perceived great risk of regular cannabis use varied significantly between 2002 and $2012 \chi^{2}(10, N=499,457)=95.35, p<0.001$, and decreased significantly from 2002 to 2012 $\left(56.5 \%\right.$ vs. $45.3 \%$, respectively) $\chi^{2}(1, N=87,837)=322.04, p<0.001$ (Table 3a). Significant variations in perceived great risk were found for all race/age subgroups, with the exceptions being individuals of Other race/ethnicity between the ages of 26-49 $\chi^{2}(10, N=10,329)=$ $2.35, p=0.015$ and age $50+\chi^{2}(10, N=3,135)=1.83, p=0.064$.

3.2.2 Men-The prevalence of perceived great risk of regular cannabis use varied significantly between $2002-2012 \chi^{2}(10, N=231,909)=38.41, p<0.001$ among men overall, and the prevalence decreased significantly when comparing 2002 and 2012 (49.0\% vs. $39.1 \%$, respectively) $\chi^{2}(1, N=40,694)=124.51, p<0.001\left(\right.$ Supplemental Table $\left.2 \mathrm{a}^{3}\right)$. The prevalence of perceived great risk of regular use varied between 2002-2012 among most race/ethnicity and age subgroups, with several exceptions: Black men age $50+\chi^{2}(10, N=$ $2,154)=0.98, p=0.447$, Hispanic men age $50+\chi^{2}(10, N=1,837)=2.53, p=0.009$, and men of Other race/ethnicity ages $12-17 \chi^{2}(10, N=7,452)=2.89, p=0.003$, ages $26-49 \chi^{2}(10, N=$ $4,638)=1.85, p=0.058$, and age $50+\chi^{2}(10, N=1,406)=1.70, p=0.094$, among whom perceived great risk of regular cannabis use did not vary significantly.

3.2.3 Women-Perceived great risk of regular cannabis use varied significantly between 2002-2012 among women overall in the NSDUH $\chi^{2}(10, N=267,548)=68.14, p<0.001$, and when comparing the prevalence of perceived great risk in 2002 and 2012 directly, the prevalence decreased significantly $(63.1 \%$ vs. $50.8 \%) \chi^{2}(1, N=47,143)=244.74, p<0.001$ (Supplemental Table $2 b^{4}$ ). Perceived great risk also varied significantly among women in most race/ethnicity age subgroups, with several exceptions: Hispanic women age $50+\chi^{2}(10$, $N=2,475)=1.27, p=0.252$, women of Other race/ethnicity overall $\chi^{2}(10, N=21,585)=$ $2.45, p=0.011$, women of Other race/ethnicity ages $12-17 \chi^{2}(10, N=7,308)=1.93$, $p=0.051,26-49 \chi^{2}(10, N=5,691)=1.83, p=0.065$, and $50+\chi^{2}(10, N=1,729)=0.94$, $p=0.476$.

\footnotetext{
${ }_{3}^{2}$ Supplementary material can be found by accessing the online version of this paper at http://dx.doi.org and by entering doi:...

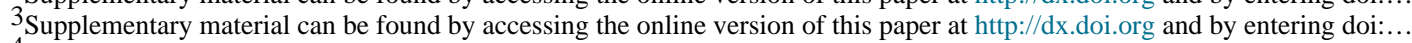

${ }^{4}$ Supplementary material can be found by accessing the online version of this paper at http://dx.doi.org and by entering doi:...
} 
3.3 Perceived risk of cannabis use among past year non-daily cannabis users: 2002-2012

3.3.1 All Past Year Non-Daily Cannabis Users-Among the total sample of past year non-daily cannabis users, the perceived great risk of regular cannabis use varied significantly between the years 2002 and $2012 \chi^{2}(10, N=92,395)=19.91, p<0.001$, and decreased significantly between 2002 and 2012 (10.8\% vs. 5.3\%, respectively) $\chi^{2}(1, N=$ $17,217)=71.00, p<0.001$ (Table 3b). Perceived great risk decreased significantly among all age subgroups of the total sample, except individuals age $50+\chi^{2}(10, N=1,748)=0.53$, $p=0.842$, and among all race/ethnicity categories overall except those of Other race/ethnicity $\chi^{2}(10, N=7,620)=2.28, p=0.035$.

3.3.2 Men-Among men who were past year non-daily users of cannabis, the perceived great risk of regular cannabis use varied significantly between $2002-2012 \chi^{2}(10, N=$ $49,606)=10.01, p<0.001$, and also decreased significantly when comparing 2002 to 2012 $\left(8.7 \%\right.$ vs. $3.9 \%$, respectively) $\chi^{2}(1, N=9,168)=27.45, p<0.001$ (Supplemental Table $\left.3 \mathrm{a}^{5}\right)$. The prevalence of perceived great risk of regular use varied significantly between 2002 2012 among White men overall $\chi^{2}(10, N=32,441)=7.40, p<0.001$ and Black men overall $\chi^{2}(10, N=6,508)=3.97, p=0.001$. There was notable variation in terms of significant change among the different race/ethnicity-age subgroups.

3.3.3 Women-Perceived great risk of regular cannabis use varied significantly among women who were past year non-daily cannabis users between $2002-2012 \chi^{2}(10, N=42,789)$ $=10.47, p<0.001$, and when comparing the prevalence of perceived great risk in the years 2002 and 2012 directly, the prevalence decreased significantly $(13.8 \%$ vs. $7.3 \%) \chi^{2}(1, N=$ $8,049)=34.65, p<0.001\left(\right.$ Supplemental Table $\left.3 b^{6}\right)$. Significant variations in perceived great risk were also observed among women of White, Black, and Hispanic race/ethnicities, with variation being observed among various race/ethnicity-age subgroups.

\subsection{Perceived risk of cannabis use among past year daily cannabis users: 2002-2012}

3.4.1 All Past Year Daily Cannabis Users-The perceived great risk of regular cannabis use varied significantly between 2002 and 2012 among the total sample of past year daily cannabis users $\chi^{2}(10, N=15,472)=3.19, p=0.001$ (Table $3 c$ ). Though the perceived risk of regular cannabis use did not vary significantly for most race/ethnicity-age subgroups between 2002 and 2012, notable exceptions included individuals between the ages of $18-25 \chi^{2}(10, N=10,060)=4.01, p<0.001$ and Whites age $18-25 \chi^{2}(10, N=6,790)$ $=4.29, p<0.001$, where perceived risk varied over the course of the decade.

3.4.2 Men-Between 2002-2012, the perceived risk of regular cannabis use varied among men who were daily cannabis users $\chi^{2}(10, N=10,591)=4.37, p<0.001$ (Supplemental Table $\left.4 a^{7}\right)$. Perceived risk did not vary significantly among the majority of race/ethnicity-age subgroups among men who were daily cannabis users.

\footnotetext{
${ }_{5}^{5}$ Supplementary material can be found by accessing the online version of this paper at http://dx.doi.org and by entering doi:... ${ }_{7}^{6}$ Supplementary material can be found by accessing the online version of this paper at http://dx.doi.org and by entering doi:...

${ }^{7}$ Supplementary material can be found by accessing the online version of this paper at http://dx.doi.org and by entering doi:...
} 
3.4.3 Women-Perceived risk of regular cannabis use remained stable among women overall between 2002 and $2012 \chi^{2}(10, N=4,881)=0.97, p=0.456$ (Supplemental Table $\left.4 b^{8}\right)$.

\subsection{Past year any cannabis use: 2002-2012}

When comparing the prevalence of any past year cannabis use in 2002 to 2012 directly, the prevalence of use was found to remain stable $\left(11.0 \%\right.$ vs. $12.3 \%$, respectively) $\chi^{2}(1, N=$ $109,347)=12.57, p=0.006$. The distribution of overall cannabis use for each year can be found in Supplemental Table $5^{9}$.

\subsection{Past year non-daily cannabis use: 2002-2012}

3.6.1 Total Sample-Among the total sample, past year non-daily cannabis use varied significantly between 2002 and $2012 \chi^{2}(10, N=614,579)=6.25, p<0.001$, but did not change significantly when comparing the years 2002 and 2012 directly $(9.7 \%$ vs. $10.2 \%$, respectively) $\chi^{2}(1, N=109,347)=2.59, p=0.110$ (Table $\left.4 \mathrm{a}\right)$. Non-daily cannabis use varied for Whites overall $\chi^{2}(10, N=391,745)=4.10, p<0.001$, all age subgroups among Whites, as well as among Hispanics overall $\chi^{2}(10, N=94,578)=4.14, p<0.001$.

3.6.2 Men-Among men, past year non-daily cannabis use varied significantly between $2002-2012 \chi^{2}(10, N=295,595)=5.60, p<0.001$, but did not differ significantly when comparing 2002 and 2012 directly $\left(11.8 \%\right.$ vs. $12.5 \%$, respectively) $\chi^{2}(1, N=52,499)=2.21$, $p=0.139$ (Supplemental Table $6 \mathrm{a}^{10}$ ). Non-daily use also varied significantly among all age subgroups of men overall between 2002-2012.

3.6.3 Women-Past year non-daily use remained stable among women overall $\chi^{2}(10, N=$ $318,984)=2.42, p=0.012\left(\right.$ Supplemental Table $\left.6 \mathrm{~b}^{11}\right)$. Women age $12-17 \chi^{2}(1, N=97,850)$ $=5.98, p<0.001$, age $50+\chi^{2}(10, N=33,367)=4.32, p<0.001$, White women age 12-17 $\chi^{2}(10, N=58,914)=7.26, p<0.001$, White women age $50+\chi^{2}(10, N=25,523)=3.63$, $p<0.001$, and Other women age $50+\chi^{2}(10, N=6,413)=0.34, p<0.001$ reported significant variations in past year non-daily cannabis use between 2002 and 2012.

\subsection{Past year daily cannabis use: 2002-2012}

3.7.1 Total Sample-Past year daily cannabis use varied significantly between 2002 and $2012 \chi^{2}(10, N=614,579)=13.42, p<0.001$, and when comparing 2002 and 2012 directly, the prevalence of daily use increased significantly between 2002 and 2012 among the population overall $(1.3 \%$ vs. $2.1 \%) \chi^{2}(1, N=109,347)=37.55, p<0.001$ (Table $\left.4 \mathrm{~b}\right)$. Significant variations in the prevalence daily use were observed among individuals age 18 $25 \chi^{2}(10, N=204,570)=9.22, p<0.001$, age $26-49 \chi^{2}(10, N=149,457)=6.74, p<0.001$, age $50+\chi^{2}(10, N=60,802)=3.64, p<0.001$. Whites overall $\chi^{2}(10, N=391,745)=9.15$, $p<0.001$, as well as the same age subgroups as the overall sample reported significant variation in the prevalence of past year daily cannabis use. Additionally, the prevalence of

\footnotetext{
${ }^{8}$ Supplementary material can be found by accessing the online version of this paper at http://dx.doi.org and by entering doi:... ${ }^{9}$ Supplementary material can be found by accessing the online version of this paper at http://dx.doi.org and by entering doi:...

${ }^{10}$ Supplementary material can be found by accessing the online version of this paper at http://dx.doi.org and by entering doi:...

${ }^{11}$ Supplementary material can be found by accessing the online version of this paper at http://dx.doi.org and by entering doi:...
} 
daily cannabis use varied significantly between 2002 and 2012 among Blacks age 18-25 $\chi^{2}(10, N=27,045)=4.36, p<0.001$, Hispanics overall $\chi^{2}(10, N=94,578)=4.10, p<0.001$, and Hispanics age $18-25 \chi^{2}(10, N=34,452)=3.57, p<0.001$.

3.7.2 Men-Past year daily cannabis use varied significantly among men in the NSDUH overall $\chi^{2}(10, N=295,595)=8.74, p<0.001$, and when comparing the prevalence in 2002 to 2012 directly, the prevalence increased significantly $(1.9 \%$ vs. $3.0 \%) \chi^{2}(1, N=52,499)=$ 34.94, $p<0.001$ (Supplemental Table $7 \mathrm{a}^{12}$ ).

3.7.3 Women-Among women overall, past year daily cannabis use varied significantly between 2002 and $2012 \chi^{2}(10, N=318,984)=6.43, p<0.001$, and when comparing 2002 to 2012 directly, increased $(0.8 \%$ vs. $1.2 \%) \chi^{2}(1, N=56,848)=11.78, p=0.001$ (Supplemental Table $7 b^{13}$ ).

\subsection{Characteristics associated with perceived great risk of regular cannabis use}

In the final adjusted model, several sociodemographic and substance use characteristics remained statistically significantly associated with perceived risk of regular cannabis use (Table 5). For instance, females had 1.74 times the odds (95\% Confidence Interval $(\mathrm{CI})=1.71-1.77)$ of reporting perceived great risk of regular cannabis use compared to men. The same pattern was observed for participants who reported Black $(\mathrm{aOR}=1.08,95 \%$ $\mathrm{CI}=1.05-1.12)$, Hispanic $(\mathrm{aOR}=1.75,95 \% \mathrm{CI}=1.69-1.81)$ and Other race/ethnicities $(\mathrm{aOR}=1.54,95 \% \mathrm{CI}=1.47-1.61)$. Compared to individuals ages 12-17, participants ages 18$25(\mathrm{aOR}=0.66,95 \% \mathrm{CI}=0.64-0.69)$ and ages $26-49(\mathrm{aOR}=0.93,95 \% \mathrm{CI}=0.90-0.96)$ had lower odds of perceiving great risk of regular cannabis use, while participants age 50 and older had higher odds ( $\mathrm{aOR}=1.37,95 \% \mathrm{CI}=1.31-1.42)$ of perceiving great risk of regular marijuana use. Participants with a high school education or greater had lower odds of reporting perceived great risk of regular use $(\mathrm{aOR}=0.75,95 \% \mathrm{CI}=0.72-0.77)$ compared to those without a high school diploma. Compared to those with a total family income of $\$ 0$ $\$ 19,999$, participants with an income of $\$ 20,000-\$ 49,999$ had an increased odds of great perceived risk ( $\mathrm{aOR}=1.06,95 \% \mathrm{CI}=1.03-1.09)$, while participants with an income of $\$ 75,000$ or greater had lower odds of perceiving great risk of regular use $(\mathrm{aOR}=0.90,95 \%$ $\mathrm{CI}=0.847-0.94)$ than those with incomes lower than $\$ 20,000$. Additionally, past year nondaily cannabis use $(\mathrm{aOR}=0.11,95 \% \mathrm{CI}=0.10-0.12)$ and past year daily cannabis use $(\mathrm{aOR}=0.04,95 \% \mathrm{CI}=0.03-0.05)$ were negatively associated with perceived great risk of regular cannabis use. Additionally, survey years 2008 ( $\mathrm{aOR}=0.88,95 \% \mathrm{CI}=0.83-0.92$ ), $2009(\mathrm{aOR}=0.77,95 \% \mathrm{CI}=0.73-0.81), 2010(\mathrm{aOR}=0.69,95 \% \mathrm{CI}=0.66-0.73), 2011$ $(\mathrm{aOR}=0.65,95 \% \mathrm{CI}=0.62-0.68)$, and $2012(\mathrm{aOR}=0.59,95 \% \mathrm{CI}=0.57-0.62)$ were associated with a reduction of the odds of perceived great risk of regular cannabis use.

\section{DISCUSSION}

Findings from this paper add to the current understanding of the temporal changes in perceived risk of cannabis use, and the correlates of perceived risk, in a U.S. nationally

${ }^{12}$ Supplementary material can be found by accessing the online version of this paper at http://dx.doi.org and by entering doi:...

${ }^{13}$ Supplementary material can be found by accessing the online version of this paper at http://dx.doi.org and by entering doi:... 
representative sample. Perceived great risk of regular cannabis use varied significantly between 2002-2012 in the U.S. among the population ages 12 and older as a whole, among both men and women, as well as among most race/ethnicities and most age subgroups. The prevalence of perceived great risk was noticeably higher among past year non-users than past year cannabis users, consistent with previous examinations of perceived risk (Kilmer et al., 2007; Lopez-Quintero and Neumark, 2010). Nonetheless, perceived great risk of regular use varied between 2002-2012 among both past year non-users and past year non-daily users of cannabis. Perceived risk varied significantly among past year daily users overall, though this finding seems to be carried by significant findings only for individuals ages 1825 . When examining past year cannabis use, non-daily and daily cannabis use increased modestly (i.e., $<1 \%$ for the sample overall), but significantly between the two time points. In terms of sex differences, the increase in non-daily use appears to be due to variation in the prevalence of use among men only, whereas the prevalence of daily use varied significantly among both men and women.

In adjusted analyses, females were more likely to perceive a great risk associated with regular cannabis use than males, which is congruent with previous findings assessing higher risk perceptions for cannabis and tobacco use (Thorton et al., 2013). Additionally, participants of non-White race/ethnicities were more likely than Whites to perceive great risk of regular cannabis use. Participants between the ages of 18 and 25 were less likely than the youngest group (ages 12-17) to perceive great risk of regular cannabis use, and as has been found in previous research (Thornton et al., 2013), older individuals were more likely than the youngest participants to perceive great risk of use.

Interestingly, individuals with a high school education or greater were significantly less likely to perceive great risk of regular cannabis use than those with less than a high school education. Though additional research is warranted to more fully elucidate this observed relationship, findings are partially corroborated by results from Gallup polls indicating that adults with a college education compared to those without are more likely to support legalization of cannabis (Carroll, 2005). In addition, we found that individuals with total family incomes over $\$ 75,000$ had significantly lower perceptions of great risk compared to those earning below $\$ 20,000$. This parallels findings from the 2008-2009 wave of the National Longitudinal Study of Adolescent Health (Add Health) study, indicating that those in the highest income bracket had the highest odds of meeting lifetime CUD criteria (Haberstick et al, 2014).

In adjusted analyses, past year cannabis users were less likely to perceive great risk associated with regular cannabis use. A dose response relationship between frequency of use and perceived risk was observed: non-daily users were $89 \%$ less likely than past year nonusers and daily users were $96 \%$ less likely than non-users to perceive great risk associated with regular cannabis use. Additionally, participants surveyed in the years 2008 through 2012 , compared to those surveyed in the year 2002, were significantly less likely to perceive great risk associated with regular cannabis use after adjusting for sociodemographic characteristics and past year cannabis use frequency. This finding further highlights the overall changes in perception even after accounting for cannabis use, as might be expected given the observed trend toward decreasing great perceived risk in the substrata assessed. 
This observation may at least partially be explained by the increasing number of states that legalized medical marijuana during 2008 and after: prior to 2008, 11 states had legalized medical marijuana, while starting in 2008, an additional 12 states and Washington D.C. passed legislation regarding medical marijuana (ProCon.org, 2014).

The present study has several limitations. All data were obtained via self-report, which may be biased due to stigma surrounding substance use. However, the NSDUH utilizes ACASI, which has been shown to increase the likelihood of honest responding for sensitive information (Macalino et al., 2002). The NSDUH cross-sectional design prevented causal inferences regarding the temporal ordering of perceived great risk and correlates.

Additionally, the NSDUH did not collect information regarding intention or desire to use cannabis, limiting possible analyses. Nonetheless, a major strength of the present study is the use of a nationally representative sample, allowing for generalization of findings to the U.S. non-institutionalized population ages 12 and older. Additionally, findings provide current estimates of temporal changes in perceived risk of regular cannabis use, as well as correlates of perceived great risk of regular cannabis use.

Perceived great risk of regular cannabis use has declined significantly over a 10-year period in the U.S., accompanied by a modest, but significant, increase in past year non-daily and daily cannabis use. Various sociodemographic and substance use variables, such as sex, race/ethnicity, age, income, educational attainment, and past year cannabis use frequency, were also associated with perceived risk of regular cannabis use. Findings regarding the prevalence of perceived great risk of regular cannabis use help characterize public opinions regarding cannabis, which are particularly relevant given the ongoing debate concerning the medicalization and legalization of cannabis in the U.S. The identified correlates of perceived risk of cannabis use may be helpful when determining which groups should be targeted for prevention interventions. Longitudinal studies are needed to assess whether the observed decline in perceived risk of cannabis use is related to future cannabis initiation and use. Additionally, studies assessing state-level cannabis laws and their impact on perceived risk of use and actual use are needed.

\section{Supplementary Material}

Refer to Web version on PubMed Central for supplementary material.

\section{References}

Brook JS, Lee JY, Finch SJ, Koppel J, Brook DW. Psychosocial factors related to cannabis use disorders. Subst Abus3. 2011; 32:242-251.

Buckner JD, Schmidt NB, Lang AR, Small JW, Schlauch RC, Lewinsohn PM. Specificity of social anxiety disorder as a risk factor for alcohol and cannabis dependence. J Psychiatr Res. 2008; 42:230-239. [PubMed: 17320907]

Budney AJ, Moore BA, Vandrey RG, Hughes JR. The time course and significance of cannabis withdrawal. J Abnorm Psychol. 2003; 112:393-402. [PubMed: 12943018]

Budney AJ, Roffman R, Stephens RS, Denise W. Marijuana dependence and its treatment. Addict Sci Clin Pract. 2007a; 4:4-16. [PubMed: 18292704] 
Budney AJ, Vandrey RG, Hughes JR, Moore BA, Bahrenburg B. Oral delta-9-tetrahydrocannabinol suppresses cannabis withdrawal symptoms. Drug Alcohol Depend. 2007b; 86:22-29. [PubMed: 16769180]

Carrol, J. Who supports marijuana legalization?. 2005 Nov 1. Retrieved from http://www.gallup.com/ poll/19561/Who-Supports-Marijuana-Legalization.aspx

Cerda M, Wall M, Keyes KM, Galea S, Hasin D. Medical marijuana laws in 50 states: investigating the relationship between state legalization of medical marijuana and marijuana use, abuse and dependence. Drug Alcohol Depend. 2012; 120:22-27. [PubMed: 22099393]

Compton WM, Grant BF, Colliver JD, Glantz MD, Stinson FS. Prevalence of marijuana use disorders in the United States: 1991-1992 and 2001-2002. JAMA. 2004; 17:2114-2121. [PubMed: 15126440]

Compton WM, Thomas YF, Conway KP, Colliver JD. Developments in the epidemiology of drug use and drug use disorders. Am J Psychiatry. 2005; 162:1494-1502. [PubMed: 16055770]

Copeland J, Swift W. Cannabis use disorder: epidemiology and management. Int Rev Psychiatry. 2009; 21:96-103. [PubMed: 19367503]

Fergusson DM, Horwood LJ, Beautrais AL. Cannabis and educational achievement. Addiction. 2003; 98:1681-1692. [PubMed: 14651500]

Furr-Holden CD, Lee MH, Milam AJ, Johnson RM, Lee KS, Ialongo NS. The growth of neighborhood disorder and marijuana use among urban adolescents: a case for policy and environmental interventions. J Stud Alcohol Drugs. 2011; 72:371-379. [PubMed: 21513673]

Gruber AJ, Pope HG, Hudson JI, Yurgelun-Todd D. Attributes of long-term heavy cannabis users: a case-control study. Psychol Med. 2003; 33:1415-1422. [PubMed: 14672250]

Guxens M, Nebot M, Ariza C. Age and sex differences in factors associated with the onset of cannabis use: a cohort study. Drug Alcohol Depend. 2007; 88:234-243. [PubMed: 17161922]

Haberstick BC, Young SE, Zeiger JS, Lessem JM, Hewitt JK, Hopfer CJ. Prevalence of correlates of alcohol and cannabis use disorders in the United States: results from the national longitudinal study of adolescent health. Drug Alcohol Depend. 2014; 136:158-161. [PubMed: 24440049]

Hall W, Degenhardt L. Prevalence and correlates of cannabis use in developed and developing countries. Curr Opin Psychiatry. 2007; 20:393-397. [PubMed: 17551355]

Harper S, Strumpf EC, Kaufman JS. Do medical marijuana laws increase marijuana use? Replication study and extension. Ann Epidemiol. 2012; 22:207-212. [PubMed: 22285867]

Janz NK, Becker MH. The health belief model: a decade later. Health Educ Behav. 1984; 11:1-47.

Kilmer JR, Hunt SB, Lee CM, Neighbors C. Marijuana use, risk perception, and consequences: is perceived risk congruent with reality? Addict Behav. 2007; 32:3026-3033. [PubMed: 17822856]

Lopez-Quintero C, Neumark Y. Effects of risk perception of marijuana use on marijuana use and intentions to use among adolescents in Bogotá, Columbia. Drug Alcohol Depend. 2010; 109:6572. [PubMed: 20060239]

Lynskey M, Hall W. The effects of adolescent cannabis use on educational attainment: a review. Addiction. 2000; 95:1621-1630. [PubMed: 11219366]

Lynskey MT, Health AC, Bucholz KK, Slutske WS, Madden PA, Nelson EC, Statham DJ, Martin NG. Escalation of drug use in early onset cannabis users vs co-twin controls. JAMA. 2003; 289:427433. [PubMed: 12533121]

Macalino GE, Celentano DD, Latkin C, Strathdee SA, Vlahov D. Risk behaviors by audio computerassisted self-interviews among HIV-seropositive and HIV-seronegative injection drug users. AIDS Educ Prev. 2002; 14:367-378. [PubMed: 12413183]

Moore BA, Budney AJ. Relapse in outpatient treatment for marijuana dependence. J Subst Abuse Treat. 2003; 25:85-89. [PubMed: 14629990]

ProCon.org. [Accessed January 6, 2015] 23 Legal Medical Marijuana States and DC: Laws, Fees, and Possession Limits. 2014. Retrieved from http://medicalmarijuana.procon.org/view.resource.php? resourceID $=000881$

Schuermeyer J, Salomonsen-Sautel S, Price RK, Balan S, Thurstone C, Min SJ, Sakai JT. Temporal trends in marijuana attitudes, availability, and use in Colorado compared to non-medical marijuana states: 2003-11. Drug Alcohol Depend. 2014; 140:145-155. [PubMed: 24837585] 
StataCorp. Stata Statistical Software: Release 12. College Station, TX: StataCorp LP; 2011.

Substance Abuse and Mental Health Services Administration. NHSDA Series H-22, DHHS Publication No SMA 03-3836. Office of Applied Studies; Rockville, MD: 2003. Results from the 2002 National Survey on Drug Use and Health: National Findings.

Substance Abuse and Mental Health Services Administration. NSDUH Series H-46, HHS Publication No (SMA) 13-4795. Rockville, MD: 2013. Results from the 2012 National Survey on Drug Use and Health: Summary of National Findings.

Stephens RS, Babor TF, Kadden R, Miller M. The Marijuana Treatment Project: rationale, design and participant characteristics. Addiction. 2002; 97(Suppl 1):109-124. [PubMed: 12460133]

Thornton LK, Baker AL, Johnson MP, Lewin T. Perceived risk associated with tobacco, alcohol, and cannabis use among people with and without psychotic disorders. Addict Behav. 2013; 38:22462251. [PubMed: 23507458]

Tucker JS, Pollard MS, de la Haye K, Kennedy DP, Green HD Jr. Neighborhood characteristics and the initiation of marijuana use and binge drinking. Drug Alcohol Depend. 2013; 128:83-89. [PubMed: 22938829]

Wall MM, Poh E, Cerdá M, Keyes KM, Galea S, Hasin DS. Adolescent marijuana use from 2002 to 2008: higher in states with medical marijuana laws, cause still unclear. Ann Epidemiol. 2011; 21:714-716. [PubMed: 21820632]

Whitlow CT, Liguori A, Livengood LB, Hart SL, Mussat-Whitlow BJ, Lamborn CM, Laurienti PJ, Porrino LJ. Long-term heavy marijuana users make costly decisions on a gambling task. Drug Alcohol Depend. 2004; 76:107-111. [PubMed: 15380295]

Wilson N, Syme SL, Boyce W, Battistich VA, Selvin S. Adolescent and alcohol, tobacco, and marijuana use: the influence of neighborhood disorder and hope. Am J Health Promot. 2005; 20:11-19. [PubMed: 16171156]

Wittchen HU, Fröilch C, Behrendt S, Günther A, Rehm J, Zimmerman P, Lieb R, Perkonigg A. Cannabis use disorders and their relationship to mental disorders: a 10-year prospectivelongitudinal community study in adolescents. Drug Alcohol Depend. 2007; 88(Supp 1):S60-S70. [PubMed: 17257779] 


\section{Highlights}

- Perceived great risk of regular cannabis use decreased between 2002 and 2012.

- Non-daily cannabis use increased between 2002 and 2012.

- Daily cannabis use increased between 2002 and 2012. 


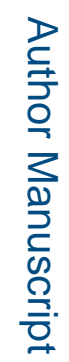

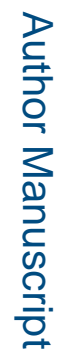

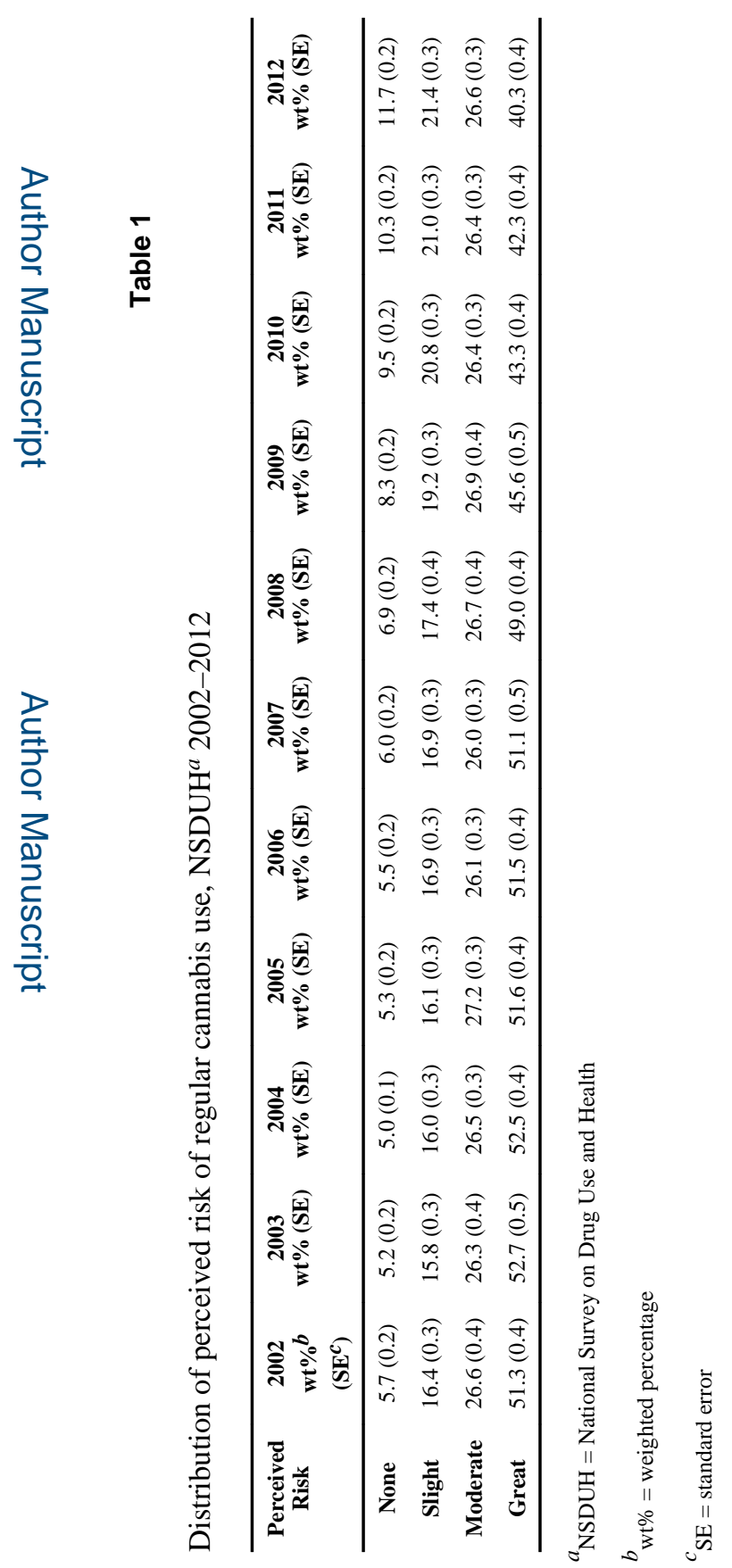




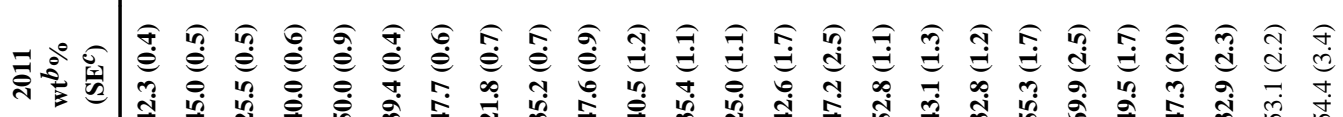

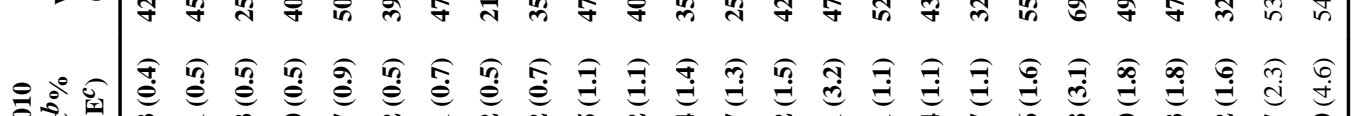

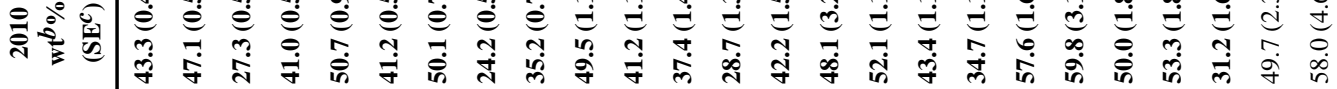
तิ

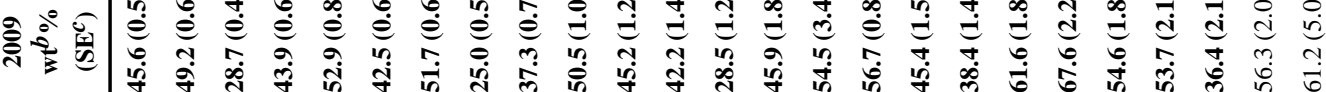

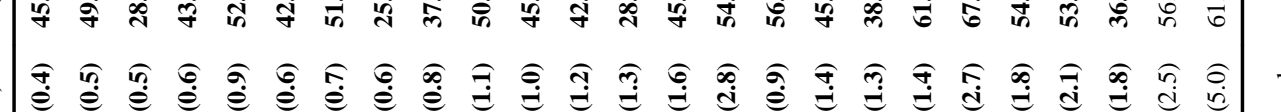

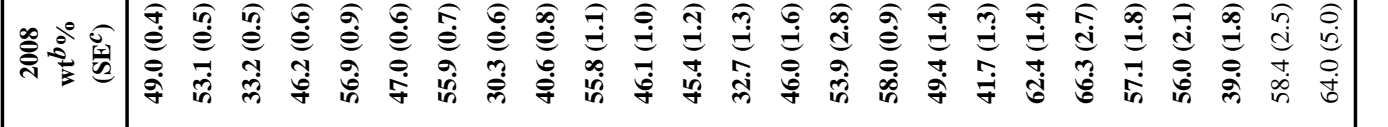

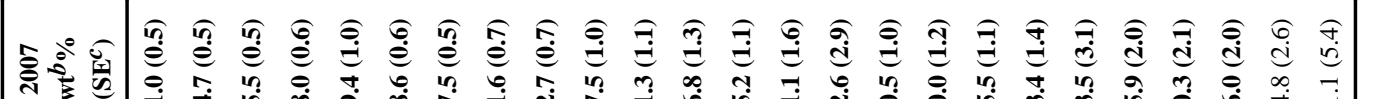
V

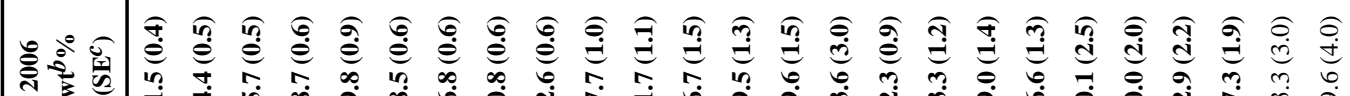

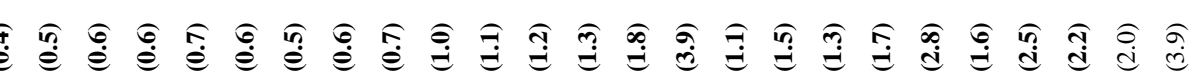
क्रा

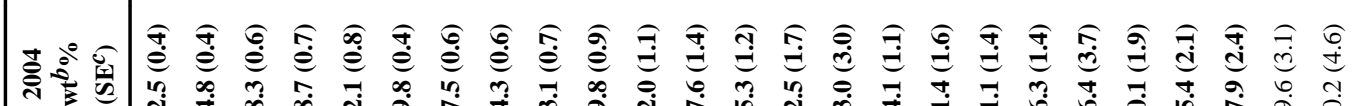

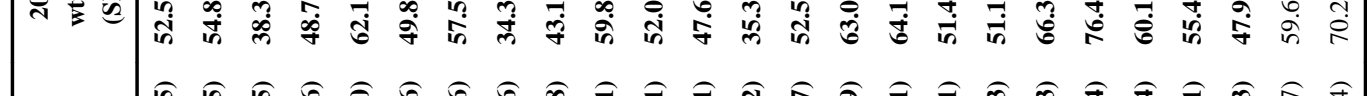

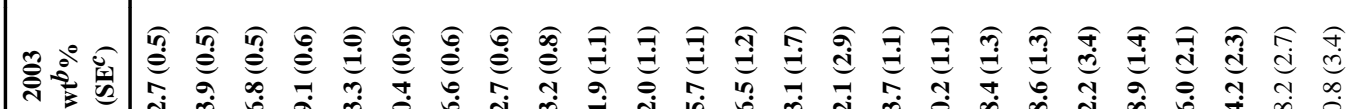

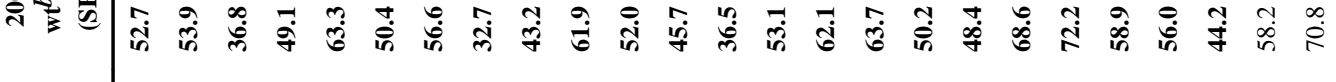

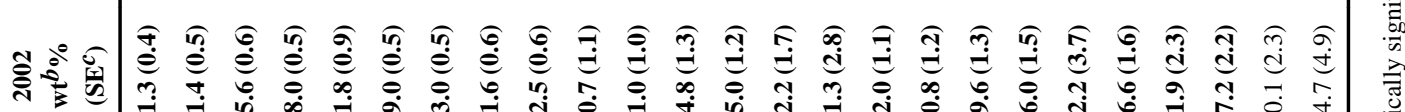

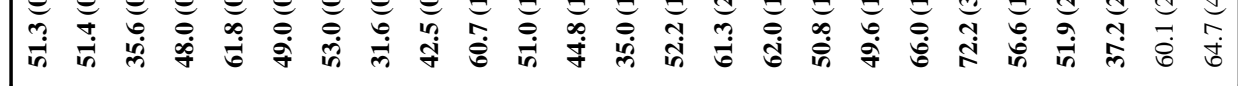

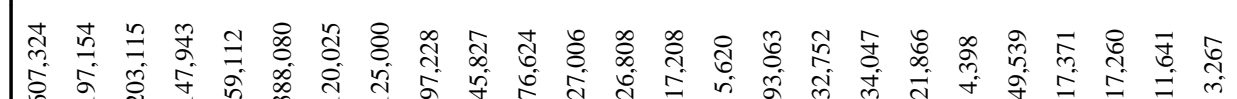

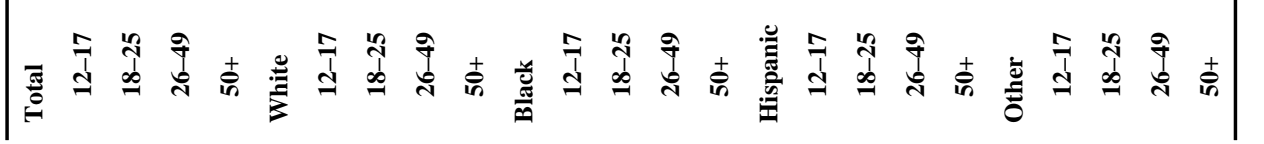




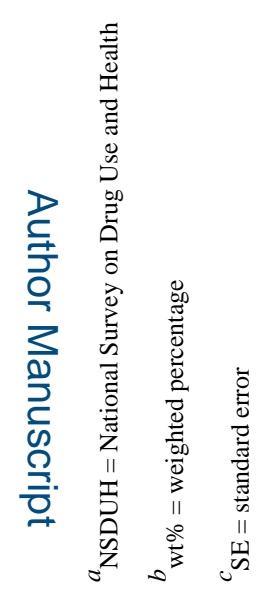

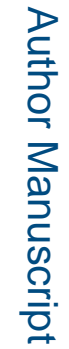

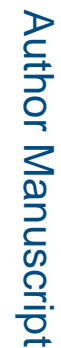

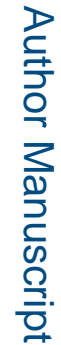

Drug Alcohol Depend. Author manuscript; available in PMC 2016 April 01 


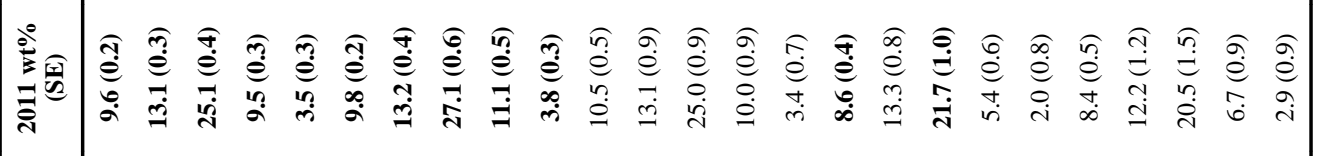




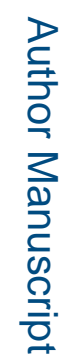

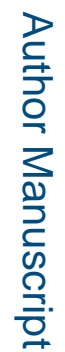

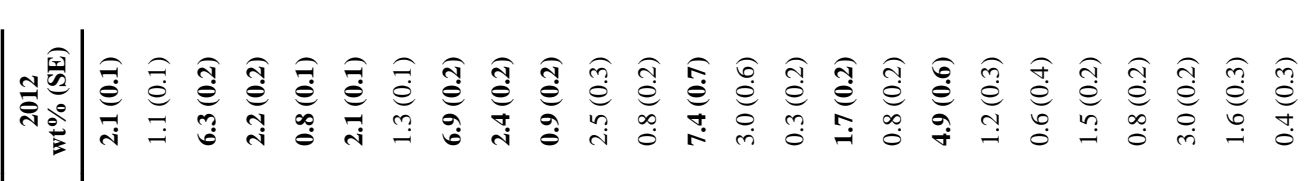

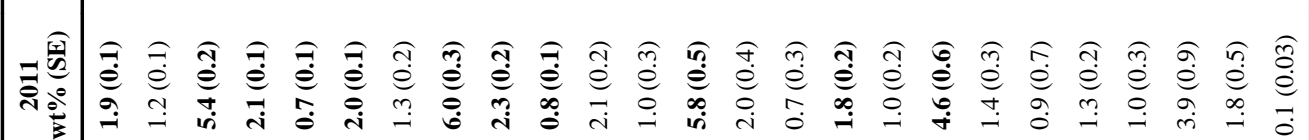

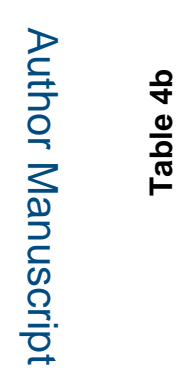

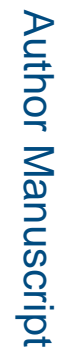

ปั

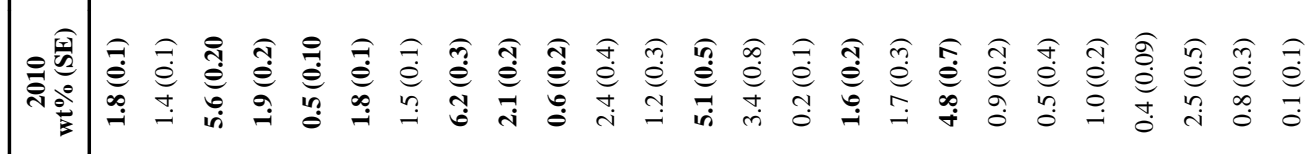

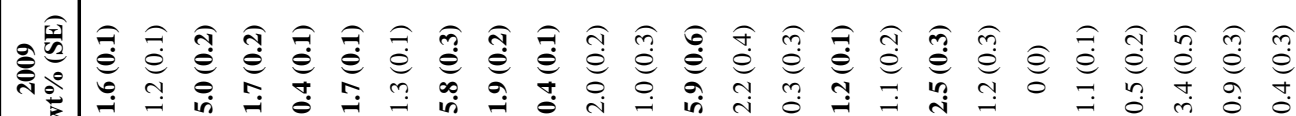

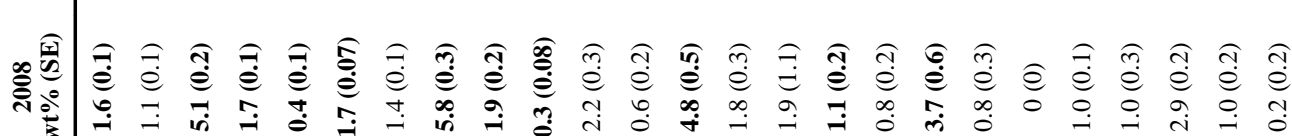

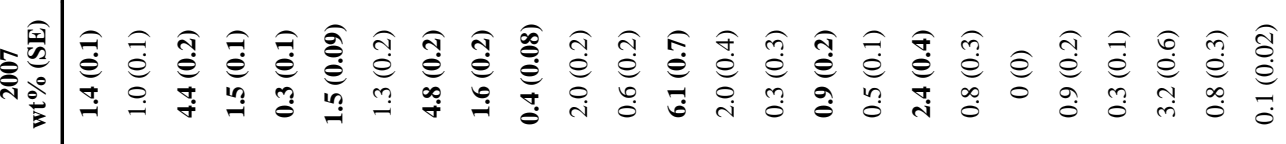

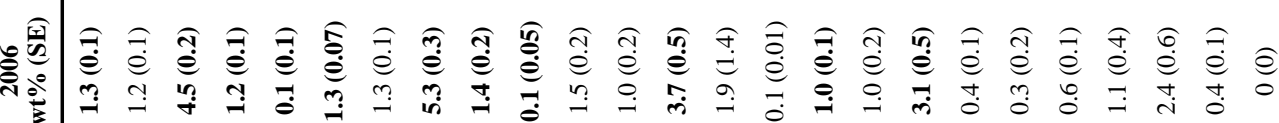

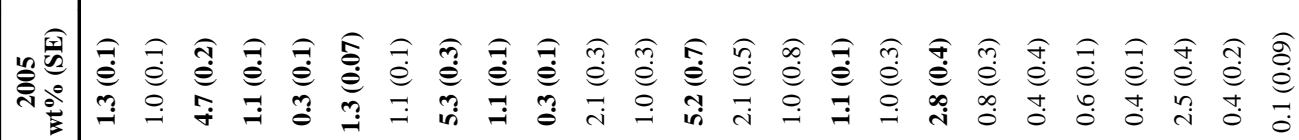

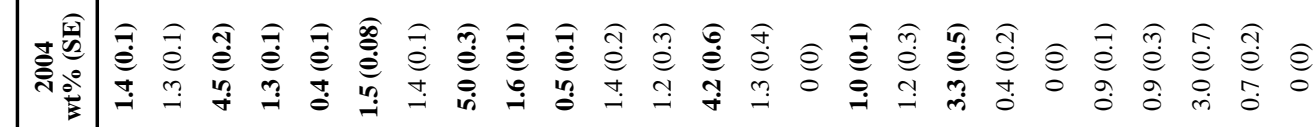

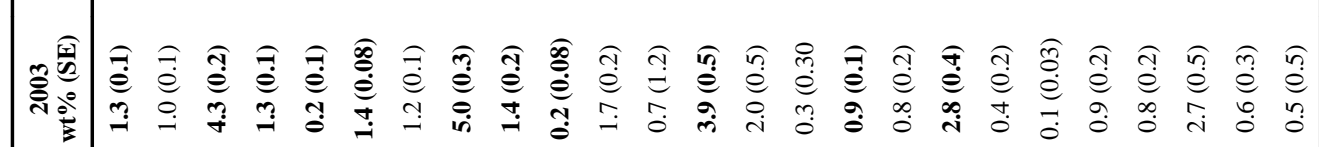

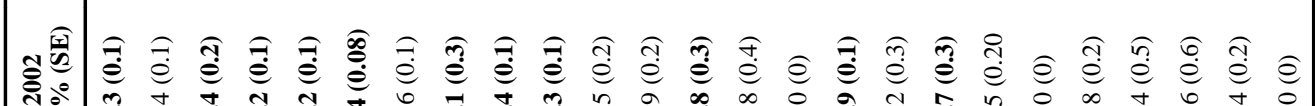

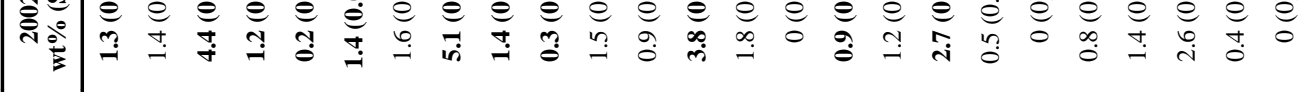

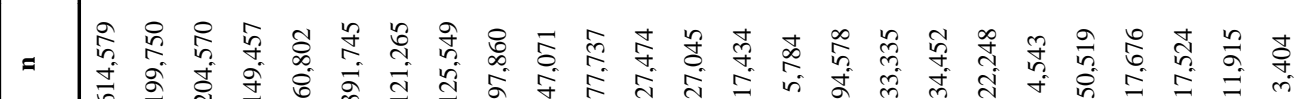

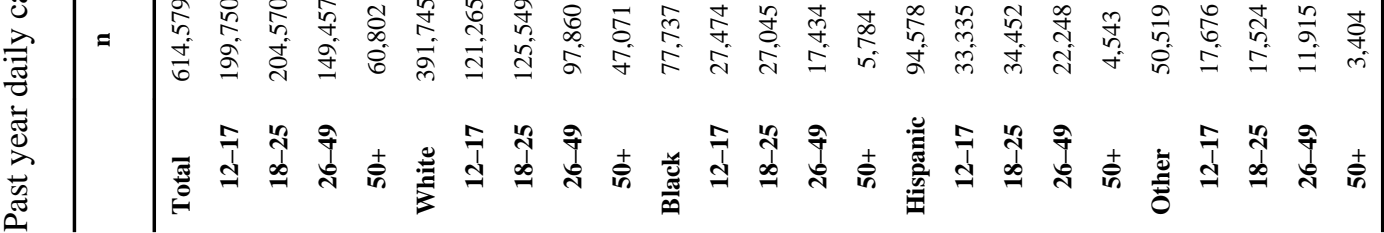




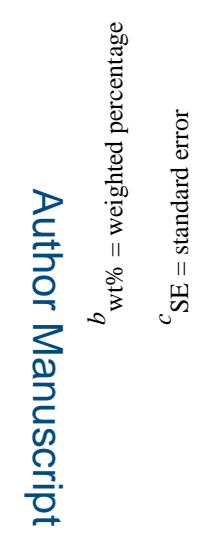

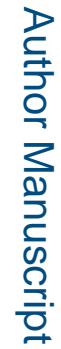

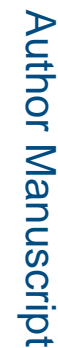

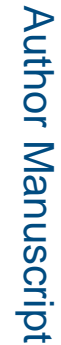

Drug Alcohol Depend. Author manuscript; available in PMC 2016 April 01 


\section{Table 5}

Adjusted odds of perceived great risk of regular cannabis use by sociodemographic characteristics and cannabis use

\begin{tabular}{|c|c|c|}
\hline Covariate & $\mathrm{OR}^{a}\left(95 \% \mathrm{CI}^{b}\right)$ & $\mathrm{aOR}^{c}(95 \% \mathrm{CI})$ \\
\hline \multicolumn{3}{|l|}{ Sex } \\
\hline Male & 1.0 & 1.0 \\
\hline Female & $1.80(1.77-1.83)$ & $1.74(1.71-1.77)$ \\
\hline \multicolumn{3}{|l|}{ Race/Ethnicity } \\
\hline White & 1.0 & 1.0 \\
\hline Black & $1.06(1.03-1.09)$ & $1.08(1.05-1.12)$ \\
\hline Hispanic & $1.65(1.61-1.70)$ & $1.75(1.69-1.81)$ \\
\hline Other & $1.44(1.38-1.51)$ & $1.54(1.47-1.61)$ \\
\hline \multicolumn{3}{|l|}{ Age } \\
\hline $12-17$ & 1.0 & 1.0 \\
\hline $18-25$ & $0.46(0.45-0.47)$ & $0.66(0.64-0.69)$ \\
\hline $26-49$ & $0.79(0.78-0.80)$ & $0.93(0.90-0.96)$ \\
\hline $50+$ & $1.23(1.20-1.26)$ & $1.37(1.31-1.42)$ \\
\hline \multicolumn{3}{|l|}{ Education } \\
\hline$<\mathbf{H S}$ & 1.0 & 1.0 \\
\hline HS+ & $0.74(0.72-0.75)$ & $0.75(0.72-0.77)$ \\
\hline \multicolumn{3}{|l|}{ Income } \\
\hline$\$ 0-19,999$ & 1.0 & 1.0 \\
\hline$\$ 20,000-49,999$ & $1.06(1.03-1.09)$ & $1.06(1.03-1.09)$ \\
\hline$\$ 50,000-74,999$ & $0.95(0.93-0.98)$ & $0.98(0.95-1.02)$ \\
\hline$\$ 75,000+$ & $0.85(0.82-0.88)$ & $0.90(0.87-0.94)$ \\
\hline \multicolumn{3}{|l|}{ Cannabis Use } \\
\hline No use & 1.0 & 1.0 \\
\hline Non-daily use & $0.09(0.08-0.10)$ & $0.11(0.10-0.12)$ \\
\hline Daily use & $0.03(0.02-0.04)$ & $0.04(0.03-0.05)$ \\
\hline \multicolumn{3}{|l|}{ NSDUH $^{d}$ Year } \\
\hline 2002 & 1.0 & 1.0 \\
\hline 2003 & $1.06(1.01-1.11)$ & $1.06(1.00-1.12)$ \\
\hline 2004 & $1.05(1.00-1.10)$ & $1.05(0.99-1.11)$ \\
\hline 2005 & $1.00(0.95-1.05)$ & $0.99(0.94-1.05)$ \\
\hline 2006 & $1.00(0.96-1.06)$ & $0.99(0.94-1.04)$ \\
\hline 2007 & $0.99(0.94-1.04)$ & $0.97(0.92-1.02)$ \\
\hline 2008 & $0.91(0.87-0.96)$ & $0.89(0.84-0.94)$ \\
\hline 2009 & $0.80(0.76-0.84)$ & $0.78(0.74-0.82)$ \\
\hline 2010 & $0.73(0.69-0.76)$ & $0.70(0.66-0.73)$ \\
\hline 2011 & $0.70(0.66-0.73)$ & $0.66(0.63-0.69)$ \\
\hline 2012 & $0.64(0.61-0.68)$ & $0.60(0.57-0.63)$ \\
\hline
\end{tabular}

Note: Bolded text indicates statistically significant differences at the Bonferroni-corrected $\mathrm{p}<0.002$ level.

Drug Alcohol Depend. Author manuscript; available in PMC 2016 April 01. 
${ }^{a} \mathrm{OR}=$ odds ratio

${ }^{b} \mathrm{CI}=$ confidence interval

${ }^{c}$ aOR $=$ adjusted odds ratio

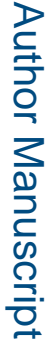

$d_{\text {NSDUH }}=$ National Survey of Drug Use and Health 